\title{
Contando Histórias, Trilhando Caminhos: A experiência da residência em saúde mental no cuidado aos trabalhadores da saúde
}

\author{
Telling Stories, Treading Paths: The experience of residency in mental health in the care of health's \\ workers
}

Contando Historias, Construyendo Caminos: La experiencia de la residencia en salud mental en el cuidado de los trabajadores de la salud

Recebido: 28/10/2021 | Revisado: 04/11/2021 | Aceito: 07/11/2021 | Publicado: 11/11/2021

\author{
Vanessa Ruffatto Gregoviski \\ ORCID: https://orcid.org/0000-0003-2404-8714 \\ Universidade do Vale do Rio dos Sinos, Brasil \\ E-mail: vanessaruffattog@gmail.com \\ Luiz Alberto dos Santos Ferreira \\ ORCID: https://orcid.org/0000-0001-7021-7238 \\ Universidade do Vale do Rio dos Sinos, Brasil \\ E-mail: luizrecre@yahoo.com.br
}

\begin{abstract}
Resumo
A saúde do trabalhador é uma temática essencial, principalmente ao compreender que o trabalho constrói o sujeito. No âmbito da saúde, há uma necessidade ainda mais nítida de cuidado a essas pessoas. Este artigo surge com o objetivo de contar a experiência vivida enquanto residente multiprofissional em saúde mental, desenvolvendo ações, pensando na saúde mental dos trabalhadores de saúde em um âmbito de gestão e na atenção básica. Trata-se de um relato de experiência que utiliza enquanto ferramentas metodológicas o diário de campo e a observação participante, constituindo-se como uma pesquisa qualitativa que utiliza a análise de conteúdo. As intervenções propostas, ainda que pontuais, tiveram impactos positivos, demonstrando a importância do afeto e da pausa para esses trabalhadores, fomentando o suporte coletivo. Desse modo, percebe-se a residência como uma possibilidade de cuidado aliado a educação permanente em saúde, pois é capaz tanto de apontar lacunas existentes, quanto de acolher as demandas de cuidado feitas.
\end{abstract}

Palavras-chave: Saúde do trabalhador; Saúde mental; Residência multiprofissional.

\begin{abstract}
Worker's health is an essential theme, especially when understanding that work builds the person. In the area of health, there is an even clearer need for care for these people. This article aims to tell the experience lived as a multidisciplinary resident in mental health, developing actions thinking about the mental health of health workers in a management context and in primary care. It is an experience report that uses as methodological tools the field diary and participant observation, constituting a qualitative research that uses content analysis. The proposed interventions, although punctual, had positive impacts, demonstrating the importance of affection and pause for these workers, fostering collective support. Thus, residency is perceived as a possibility of care combined with continuing education in health, as it is capable of pointing out existing gaps and doing something about the care demands made. Keywords: Workers' health; Mental health; Multiprofessional residency.
\end{abstract}

\section{Resumen}

La salud del trabajador es un tema fundamental, especialmente cuando se comprende que el trabajo construye el tema. En el campo de la salud, existe una necesidad aún más clara de atender a estas personas. Este artículo tiene como objetivo relatar la experiencia vivida como residente multidisciplinar en salud mental, desarrollando acciones pensando en la salud mental de los trabajadores de la salud en un contexto de gestión y en la atención primaria. Es un relato de experiencia que utiliza como herramientas metodológicas el diario de campo y la observación participante, constituyendo una investigación cualitativa que utiliza el análisis de contenido. Las intervenciones propuestas, aunque puntuales, tuvieron impactos positivos, demostrando la importancia del cariño y la pausa para estos trabajadores, fomentando el apoyo colectivo. Así, la residencia se percibe como una posibilidad de atención combinada con la educación continua en salud, ya que es capaz tanto de señalar las brechas existentes como de acoger las demandas de atención que se plantean.

Palabras clave: Salud del trabajador; Salud mental; Residencia multiprofesional. 


\section{Introdução}

A discussão acerca a saúde do trabalhador é uma temática notória e amplamente discutida de forma interdisciplinar, sendo uma temática essencial à Saúde Coletiva. Impreterivelmente, com o sistema neoliberal em vigor, falar-se-á sobre o desenfreado aumento da flexibilização laboral e precariedade nos ambientes de trabalho, ocasionando sofrimento aos trabalhadores com possíveis impactos em sua saúde mental e desorganizações coletivas (Barros \& Bernardo, 2017; Antunes, 2018; Gomez, Vasconcellos \& Machado, 2018; Patrício \& Gregoviski, 2020).

Os relatos de dor-desprazer-trabalho são frequentes e evidenciam a necessidade de se pôr em análise as mudanças vivenciadas socialmente, questionando-se o modelo de produção em voga. Porém, em termos práticos, o que vem sendo construído? Há a necessidade de se pensar em estratégias promotoras de saúde integral e acolhimento aos sofrimentos que emergem nesse contexto, ainda que existam impasses que requeiram ser superados para essas construções potentes. Essas reflexões permearam a discussão tecida nesta reflexão (Heloani \& Lancman, 2004; Barros e Barros, 2007; Patrício \& Gregoviski, 2020).

Dessa forma, esta reflexão se propõe a aproximar prática e teoria através de um relato das experiências vivenciadas enquanto psicóloga residente multiprofissional de saúde mental, pensando espaços de cuidado ao trabalhador da saúde em diversos níveis de assistência. Esta vivência se tornou foco de análise ao se perceber a riqueza de possibilidades pouco exploradas (na teoria e na prática) envoltas no olhar da Residência sob esses sujeitos, frequentemente esgotados e entorpecidos diante do cenário que se apresenta, mas que, ainda assim, seguem executando sua função de cuidado com o Outro.

Esclarece-se que os programas de Residências Multiprofissionais em Saúde (RMS) são estratégias de ensino em serviço, nos quais profissionais graduados da área da saúde tem a possibilidade de aprimoramento técnico por intermédio da inserção prático-teórica de 60 horas semanais ao longo de dois anos. Logo, há um claro objetivo de formação profissional contínua e especializada para trabalho no Sistema Único de Saúde (SUS). Ademais, são, também, instrumentos essenciais para a educação permanente em saúde, qualificação necessária para o aprimoramento de práticas de cuidado. As RMS na área de saúde mental, além de pautadas nos princípios e diretrizes que orientam o SUS, também defendem o cuidado antimanicomial e em liberdade, conforme pregado pela Reforma Psiquiátrica Brasileira, e compreende que a saúde mental está muito além de diagnósticos fechados, porque se trabalham com seres humanos permeados por desejos e anseios, logo, necessitando-se fomentar vida e promover saúde a partir de uma visão biopsicossocial (Brasil, 2001; Brasil, 2005; Brasil, 2007; Brasil, 2009; Brasil, 2012; Ceccim, 2014; Silva et al., 2016; Silva \& Dalbello-Araujo, 2019).

Assim, nesses espaços de trabalho do profissional residente, existe um arcabouço de possibilidades de estratégias de cuidado a depender de onde se dá a inserção. Nesta pesquisa, a residente esteve inserida em um cenário de atenção básica e um de gestão municipal, e se propôs a pensar em uma estratégia que assistisse aos funcionários desses espaços, ao perceber o quanto isto se fazia necessário e ocasionaria reflexos no cuidado aos pacientes. Ademais, houve a compreensão de que o trabalho estaria estreitamente relacionado a constituição dos sujeitos e sua identidade socioprofissional.

Apoiando esse princípio, Mendes (2008) coloca que a estruturação psíquica e social dos sujeitos está perpassada pela busca de prazer e reconhecimento nos ambientes laborais. Entende-se que o sofrimento sempre estará presente na dinâmica de trabalho, porém ele pode ter um destino criativo, ao ser ressignificado, ou um destino patogênico, ao causar sofrimentos intensos que podem ocasionar em adoecimento psíquicos. Ademais, a Organização do Trabalho pode colocar essa dinâmica em xeque, pois pode ser de uma gestão que preconiza a autonomia e saúde dos sujeitos, ou pode ser prescritiva e coercitiva. Estas últimas, podem reforçar a criação de ambientes hostis e sem cooperação entre os trabalhadores do coletivo, favorecendo o individualismo e solidão. (Dejours, 1991; Heloani \& Lancman, 2004; Mendes, 2008; Bouyer, 2010; Giongo, Monteiro \& Sobrosa, 2015; Monteiro, Vieira \& Mendes, 2015). 
Dessa forma, entende-se que a identidade dos sujeitos se forma nesse espaço que é tanto de produção material quanto social, sendo o reconhecimento um aspecto essencial para isto. O reconhecimento estaria, então, junto aos processos de valorização e satisfação, assim, ao não ocorrer, pode colocar os sujeitos em risco ao desencadear vivências de sofrimento e estressoras. Além de que, tais aspectos estariam relacionados à saúde mental dos sujeitos, sendo propício sua análise ao abordar a temática de saúde laboral (Martinez \& Paraguay, 2003; Heloani \& Lancman, 2004; Ferreira, 2008; Bendassolli, 2012; Giongo, Monteiro \& Sobrosa 2015).

No cenário econômico vigente, é cada vez mais exigido ao trabalhador a flexibilização de suas ações e de seu fazer, sendo que aquele que não se adaptar estará sujeito ao não reconhecimento de um trabalho efetivo. Pensando nesse contexto, pode-se afirmar que a capacidade de mudança e adaptação são constantemente testadas, podendo ou estimular a criação de solução individuais e coletivas, ou gerando adoecimento diante do cenário de produção fatalista vivido, influenciando também na constituição do sujeito e sua própria motivação ao labor (Ribeiro et al., 2011; Bendassolli, 2012; Barros \& Bernardo, 2017; Dourado \& Zambroni-de-Souza, 2020).

Nesse sentido, cabe o questionamento de qual pode ser o espaço de cuidado possível, almejando a integralidade dessas ações e colocando como alternativa ante os baixos financiamentos públicos, a tecnologia leve para tal. Pensa-se na possibilidade de que as equipes de trabalho se tornem um apoio, possibilitando, inclusive, o desenvolvimento da coletividade, importante até mesmo para reinvindicações (Mehry \& Franco, 2003; Oliniski \& Lacerda, 2006; Mendes, 2008; Bouyer, 2010; Patrício \& Gregoviski, 2020).

Isso não ocorre diferentemente no trabalho na área da saúde. Há peculiaridades importantes nessa classe, pois são trabalhadores que atuam com o cuidado ao sofrimento humano em suas formas mais extremas, deparando-se com angústias, incertezas, frustrações e sentimento de impotência. Há fatores, em conjunto com as agitações cotidianas, que levam o trabalhador a buscar formas de enfrentar as durezas às quais é submetido, porém, por vezes, a resposta se dá com outros enrijecimentos, como o desinteresse pelo outro, a robotização dos atendimentos, e o próprio não-cuidado de si enquanto profissional e sujeito (Oliniski \& Lacerda, 2006; Silva et al., 2015; Bastos, Quintana \& Carnevali, 2018).

Isso se reflete de forma direta nas dinâmicas dos serviços, tanto na dinâmica visível ao usuário e que nele toma forma (atitudes de descaso, irritabilidade, entre outros), como nas relações internas da equipe (rivalidades entre colegas, desentendimentos, adoecimento, entre outros). Em ambientes em que o contato com o sofrimento humano é um hábito, é importante pensar sobre como se produz saúde aos que ali estão realizando seus fazeres laborais (Silva et al., 2015). Como resistir às lógicas instituídas, estranhando-as e modificando-as?

Por vezes, a Organização do Trabalho não estimula a criação de espaços de coletividade e autocuidado, porém, outras tantas, o próprio trabalhador desacredita que esse cuidado pode ser realizado. Não é infrequente os discursos de suas partes referindo que intervenções de cunho de saúde laboral são ineficazes, demonstrando descrença, exaustão e desesperança. Há um sofrimento não elaborado no confronto com o real do trabalho, marcado por situações inesperadas e incômodas. Ademais, precisa-se pensar que o trabalhador da saúde não está em uma bolha alheia aos problemas sociais, pelo contrário, dessa forma, sentem em seus corpos a desvalorização do capital humano e a ineficácia de muitas ações políticas (Oliniski \& Lacerda, 2006; Rollo, 2007; Dejours, 2014).

Isso dito, entende-se que é fundamental o desenvolvimento de ações que fomentem a coletividade dos profissionais da saúde, tornando possível a luta da classe em prol de reinvindicações tão necessárias, assim como um suporte diante de momentos tão complexos como os que se experenciam (Patrício \& Gregoviski, 2020). Este relato objetiva contar como se deu o processo de cuidado a trabalhadores da saúde, propondo uma possibilidade de atuação do residente em saúde mental ao entender que está diretamente relacionado ao cuidado do usuário e à educação permanente em saúde. 


\section{Percurso Metodológico}

Este trabalho se constitui como uma pesquisa de cunho qualitativo e transversal. Toma forma através de um relato de experiência, escolha feita por conta da pesquisadora ser participante do processo. A vivência ocorreu ao longo de sete meses no ano de 2018.

Os colaboradores dessa pesquisa são trabalhadores da rede de saúde que em algum momento vivenciaram as ações voltadas à saúde mental do cuidador propostas por residentes em saúde mental. Pertence a essa categoria técnicos, gestores, coordenadores, estagiários e demais residentes. No que se refere a categoria profissional, ela também é variada, englobando médicos (as), enfermeiros (as), técnicos (as) de enfermagem, psicólogos (as), assistentes sociais, agentes comunitários de saúde, assistentes administrativos, nutricionistas e dentistas.

Os campos de atuação prática observados durante esse processo incluem um local com foco na gestão da saúde e outro voltado ao atendimento para os usuários de uma determinada localidade (atenção básica). Visando manter a ética e o sigilo, e por se tratar de um trabalho que terá como foco a experiência da pesquisadora independentemente dos lugares em que ocorreu, não serão mencionados locais e tampouco falas específicas dos profissionais e, ao utilizar das experiências desenvolvidas em um determinado cenário, utilizar-se-á um nome fictício: "Cenário Girassol" e "Cenário Roseiral".

A ferramenta de produção de dados foi o diário de campo, construído ao longo dessas interlocuções. Fragmentos foram incorporados ao texto, de forma literal ou não, e discutidos. As escritas se deram de forma regular, buscando manter a veracidade dos fatos e percepções. A observação participante também foi utilizada enquanto recurso metodológico, principalmente por se tratar de uma realidade em que a pesquisadora esteve inserida.

No tangente aos procedimentos éticos, essa pesquisa foi encaminhada e aprovada pelo Núcleo Municipal de Educação em Saúde Coletiva (NUMESC), da Secretaria Municipal de Saúde da cidade em que essas experiências se deram. Ademais, também foi seguida a Declaração de Helsinki. O sigilo foi garantido, não sendo citados nomes de pessoas e tampouco de serviços. Os escritos, ao final do trabalho, foram apresentados aos servidores.

As análises realizadas aqui podem contribuir na qualificação de processos de trabalho, bem como auxiliar a pensar fluxos de cuidado ao cuidador. Essas análises foram possíveis graças aos dados percebidos e produzidos nas ações já mencionadas. A discussão se dará através da análise de conteúdo, conforme proposto por Bardin (2011).

\section{Resultados e Discussão}

Vive-se em um período crítico. O congelamento de investimentos no sistema de saúde após o atentado à democracia está gerando precarizações e desmantelamento de serviços essenciais para o cuidado dos usuários. Em contextos de desmonte de serviços públicos, há a necessidade de se ter um especial cuidado para que a residência continue com sua potência emancipadora, para que não caia em uma lógica de mão de obra de baixo custo, como muitos esperam e/ou tensionam (Mendes, 2016).

A RMS da área da saúde mental está presente na cidade em questão há alguns anos, sendo 2018 o seu primeiro ano de inserção em campos que trabalham a partir de um viés de gestão da saúde e de atenção primária. Esta inserção se deu por uma solicitação das próprias residentes ao longo do ano anterior para que fosse possível ocupar diversos espaços em que a saúde mental se faz presente, indo além dos campos existentes até o momento.

Pensar saúde mental fora dos espaços consolidados foi um grande desafio frente às forças que remetem a um fazer especialista e segregado, entendendo a saúde mental como um campo único de Centros de Atenção Psicossocial (CAPS) ou internações hospitalares em leitos de saúde mental. Sem desvalidar a importância desses serviços para a Reforma Psiquiátrica, foi proposto uma ampliação do fazer através de uma inserção ampla e coerente com o olhar integral e intersetorial proposto e, com isso, inúmeras potencialidades em território foram exploradas. 
O cenário que trabalha a partir do olhar da gestão, de uma forma diferente que nos demais, mostrou-se um desafio dado o grande número de processos que acontecem concomitantemente. Percebe-se a necessidade de que esses trabalhadores atuem de forma ágil e com certa flexibilidade para que seja possível encarar as demandas necessárias (Martins \& Waclawovsky, 2015). Além dos diários compromissos já pré-estabelecidos, é constante o que lá é chamado de "estourar de bombas". Após o período de permanência inicial (habituação), foi possível observar o quanto essas "bombas" muito surgiam por conta de problemas de relacionamentos interpessoais e estresse dos trabalhadores da rede de saúde, fatores diretamente ligados ao sofrimento laboral. Destaca-se a percepção de que a saúde não tem relação com a ausência de sofrimento, mas sim com a possibilidade de superar esses sofrimentos e as adversidades presentes, vivenciando experiências de prazer em seu cotidiano profissional (Giongo, Monteiro \& Sobrosa, 2015). E é nesse espaço de gestão que surgem, desde o primeiro momento, apontamentos da necessidade de um cuidado e um olhar mais atento à saúde do trabalhador de uma forma ampliada, pedido este feito pelos próprios funcionários.

É importante ressaltar que em momento algum isso foi algo direcionado ou relegado à responsabilidade das residentes, porém foi impossível não ter um autoquestionamento sobre como essas pessoas conseguiam doar um pouco de si todos os dias estando tão desgastadas. Assim, pensou-se sobre qual o papel da Residência diante disso, e se seria esta mais uma instância que ignoraria um pedido de auxílio ou não.

Buscando ouvir esse pedido, pensou-se em algumas estratégias em diversos âmbitos e com alguns atores específicos em um primeiro momento (funcionários da atenção básica). A proposta foi acolhida pela preceptora (profissional designada para orientar as residentes), que se mostrou prontamente disposta a auxiliar no que fosse possível. Apresentou-se essa proposta também aos trabalhadores de um dos setores da gestão, com o objetivo de partilhar fazeres, e essas pessoas pediram para que também pudessem fazer parte disso, queriam esse olhar e esse cuidado. Relataram que nunca tiveram um espaço semelhante e trouxeram à tona toda a carga que existe quando se trabalha diretamente na gestão da saúde. Assim, esse projeto foi ampliado para que se incluísse aqui também o cuidado aos gestores, buscando promover saúde mesmo que em pequenas ações de valorização de trabalho.

\subsection{Cenário Girassol}

Quando se discursa acerca de intervenções feitas com trabalhadores da saúde é comum que se pense nas ações desenvolvidas com servidores que trabalham na assistência, atendendo diariamente usuários nas mais variadas condições. Gestores, percebendo o quanto os trabalhadores estão cansados e sofrendo, colocam o cuidado com essas pessoas antes do cuidado a si mesmo. Cabe aqui a reflexão sobre a falta de espaços de cuidado em saúde àqueles que ocupam uma posição de gestão, mesmo que se percebam impactos de estresse laboral em suas vidas tanto em uma esfera pessoal quanto profissional (Sousa \& Barros, 2018; Pires et al., 2019).

"E assim, em uma reunião para contar sobre o que queríamos fazer com outros serviços, surgiu um pedido em tom de brincadeira, mas que se mostrou muito sério: também queremos!” (Fragmento do Diário de Campo). Girassol demonstrou, através de formas sutis, que pedidos de cuidado surgem nos mais diversos espaços e que se não forem observados atentamente se pode deixar passar um local com muita potência a ser trabalhada, talvez somente voltando o olhar a essas pessoas quando a situação se tornar insustentável, e ignorando possibilidades de cuidados pautados em tecnologias leves, como o acolhimento, a escuta e a afetividade (Mehry \& Franco, 2003).

Além disso, quando se fala em saúde do trabalhador é fato costumeiro relacionar à doença do trabalhador, como se para espaços de saúde surgirem fosse necessário antes seguirmos uma lógica que preza o adoecimento. Pensa-se também em locais com pouca rede de apoio interna entre os próprios funcionários. Essa experiência se caracterizou exatamente pelo contrário. Ouvir esse pedido de cuidado sinaliza a importância do sentimento de pertença em uma equipe, construindo-se redes 
de apoio que auxiliam a tolerar o intolerável, e fomentando o envolvimento desses gestores com suas equipes, aspecto que necessidade ser mais bem investigado em suas nuances para compreensão de como se dão as relações naquele espaço e o engajamento da gestão (Böttcher \& Monteiro, 2020). Assim, a capacidade de se afetar, torna-se protetiva.

A afet(ação) e coletividade podem adquirir caráter revolucionário e podem alterar totalmente uma dinâmica de trabalho, fomentando vínculos entre as pessoas, possibilitando espaços de compartilhamento e pausa mais tranquilos. Além do que, tudo isso reflete diretamente no trabalho que é desenvolvido, conforme o que foi observado nesta experiência prática.

É visível que até mesmo nesses espaços [...] o desgaste se faz presente. E o cansaço também! O cansaço vem de várias formas, estresse, não cuidado de si..., porém é interessante perceber que mesmo em falas que remetem a isso as pessoas ainda têm como apontar pontos positivos no trabalho, especialmente no sentido de quanto a presença de algumas pessoas o torna mais leve e viável (Fragmento do Diário de Campo).

Assim, diferente de algum dos outros contextos trabalhados, quando esse pedido por um cuidado surge vem o que é chamado no diário de campo de "espaço de afeto", e "o quão incrível é poder enxergar em pleno ambiente da gestão, muitas vezes considerado rígido, duro e burocrático, esse afeto surgir" (Fragmento do Diário de Campo). Foi perceptível que seria importante pensar em algo que permitisse a esses trabalhadores um momento de pausa, de olhar para si e pensar em como é importante ter esse tipo de cuidado. Caso contrário, somente poderia ser perceptível quando a sobrecarga fosse insuportável e os "incêndios" não conseguissem mais ser "apagados".

A proposta, desenvolvida naquele momento por duas psicólogas residentes em saúde mental, pensou na oferta de um espaço de cuidado (ainda que não de forma contínua, visto que a atuação de residentes nos campos é temporária), utilizando-se da data que comemora o dia do trabalhador para tal. As ideias fluíram com grande facilidade, o que foi possível graças à abertura que o espaço proporcionava para isso. Pensou-se em estratégias que pudessem fomentar a discussão de como se dá o "cuidado de mim para comigo mesma", porém as dificuldades se esbarraram nas burocracias e tempo disponível.

Após inúmeras marcações e desmarcações, reservas de salas que não foram possíveis, foi encontrada uma forma de conciliar o cotidiano caótico com um espaço de tranquilidade. Pode-se dizer que foi possível experenciar a dificuldade que essas pessoas relatavam que tinham em parar, respirar e pensar em espaços de cuidado.

Após esse momento, pensou-se em manter essa atividade como uma surpresa até que acontecesse, deixando agendada para todos os trabalhadores uma reunião específica, pensando também na lógica de que quanto mais se segue o fluxo de um cotidiano caótico, mais nos se insere nele e se fica sem descanso, acreditando que espaços de cuidado não são prioritários quando comparados a algo tido como urgente. Essa foi uma estratégia interessante, inclusive para a garantia de liberação da agenda dessas pessoas para participação no espaço proposto.

Segundo Oliniski e Lacerda (2006), o bem-estar das pessoas está condicionado a diversas variáveis (externas e internas) que atuam e afetam o sujeito no que se refere à saúde. As autoras colocam que entre as qualidades internas, pode-se citar atividades mentais, espirituais e laborais, sendo necessário possibilitar "a reconstituição em todos os níveis e potencializa a totalidade, beleza, conforto, dignidade e paz em um ambiente sutil de energia e consciência" (p. 101). Pensando nisso, a ação sugerida foi uma "manhã de yoga na gestão".

Com o auxílio de uma instrutora convidada, iniciou-se a manhã com um ambiente repleto de colchonetes e trilha sonora adequada para completar a ambientação. Todas foram convidadas a se sentar no lugar que se sentissem mais confortáveis, colchonetes ou cadeiras. A dinâmica deu início ao se comentar sobre o porquê da reunião naquele espaço. A instrutora fez uma fala que complementou muito bem a escrita que tinha sido feita pelas residentes para o momento, falando de afetos, de cuidado, de descanso, e olhar-se. 
Nem sempre nos permitimos parar. Não para pensar, não para respirar e tampouco nos perceber ou descansar. E parar aqui não significa tirar férias, algumas folgas ou simplesmente não pensar em trabalho, mas sim, perceber as nossas emoções, os nossos sentimentos, as nossas sensações e tudo aquilo que nos afeta de alguma forma, dando passagem para a emoção, em vez da razão. Temos urgência, demandas que nos esgotam, que lotam nossas mesas e caixas de email. Temos urgência porque trabalhamos visando o cuidado de diversas pessoas, muito além daquelas que nos rodeiam. Mas será que temos urgência com as nossas próprias demandas também? Ou acabamos colocando estas em segundo plano para cuidar do outro? Percebemos o sofrimento... percebemos nossa limitação diante desse sofrimento... e isso nos frustra, nos cansa, e pode nos adoecer. Será que percebemos as nossas emoções diante de tudo que nos rodeia e acaba nos afetando? Será que conseguimos refletir a respeito da nossa própria saúde, física e mental? Âs vezes é preciso parar, descansar o corpo, para que então a alma não adoeça. Às vezes é preciso parar, descansar a alma, para que então o corpo não adoeça. Que esse não seja um espaço único, que possamos nos olhar diariamente, abraçar nosso colega e reconhecer e a importância daquilo que estamos fazendo, daquilo que nos move e nos comove. Esperamos que essa intervenção possa nos ajudar a encarar cada dia com um pouco mais de leveza, e com a certeza de que a nossa saúde é fundamental para que seja possível promover a saúde do outro (Texto escrito pelas residentes e lido no momento da ação).

Após essas falas introdutórias, aconteceu, por aproximadamente duas horas, uma prática de yoga que poderia facilmente ser aplicada em casa, concentrada em diversos momentos de respiração e percepção de si e do ambiente, inclusive com a ideia de que, posteriormente, os que se sentissem bem com esse espaço pudessem reproduzi-lo com facilidade. A prática foi bem recebida por todas, que buscaram aproveitar ao máximo os conhecimentos compartilhados.

Ao final da prática foi entregue para todas um cartão como lembrança e foram convidadas a participar de um café da manhã, com o intuito de interação e fechamento do dia, como bem sinalizaram as trabalhadoras: "fechamento com afeto" (Fragmento do Diário de Campo). Ao longo do café foi feita a avaliação da atividade que foi tida como positiva, e ficou o desejo para que momentos assim pudessem se repetir mais vezes ao longo dos espaços de trabalho, por desopilar um pouco da correria diária.

Apesar de a ação ter sido considerada muito positiva, também por fomentar espaços de trocas e ressignificações, não foi possível conciliar um novo espaço de cuidado antes da finalização do percurso das residentes, pelas dificuldades já mencionadas neste escrito. Porém, ao longo dos meses aconteceram diversos espaços informais de trocas e confraternizações, que foram avaliados como muito pertinente a manutenção desse clima de coleguismo existente no setor.

Questiona-se o porquê de práticas assim não serem corriqueiras, visto que, na lógica seguida pelo mercado, são espaços que não tomam muito tempo e não tem um custo significativo, constituindo-se também em, como coloca Mehry \& Franco (2003), uma tecnologia leve. Mas, até o momento, não há uma conclusão satisfatória sobre tal questionamento. Por fim, coloca-se que nos diários de campo há sublinhado dois pontos considerados essenciais nesta experiência: "potência do encontro" e "potência da pausa". A palavra potência, não usada ao acaso, denomina bem a construção deste espaço.

\subsection{Cenário Roseiral}

Na segunda experiência relatada, não foi possível ignorar o quanto o desmantelamento das políticas públicas vigentes afeta a saúde dos trabalhadores da assistência, bem como os serviços em si. Santos e Kuhn (2021) colocam a essencialidade da atenção básica como garantia de cuidado integral e emancipador aos usuários, ilustrando um cenário no qual isto não ocorre conforme o proposto, logo, coloca-se que é pertinente uma análise esmiuçada do contexto social e laboral em que esse cuidado deve ocorrer, já que isto favoreceria a discussão sobre como isto pode ocorrer diante de sucateamento e adoecimento daqueles que atuam nesses espaços. Muitas das escritas presentes no diário de campo têm esse cunho crítico, que levanta diversos questionamentos a respeito do que será em um futuro não distante no que se refere aos serviços públicos, sejam eles de saúde, assistência, educação ou qualquer outro.

Porém, partindo do princípio, o entendimento da necessidade de se pensar saúde mental dos trabalhadores nesse local surge de duas vias diferentes. A primeira foi a percepção obtida na inserção no campo, após observar as dinâmicas e 
funcionamento do serviço, observação essa que durou cerca de um mês. Notou-se um ambiente em que as relações eram causa de intenso sofrimento aos trabalhadores do local, refletindo diretamente no cuidado daqueles que frequentavam o serviço buscando auxílio. Já a segunda via, que veio surgindo aos poucos ao longo dessa inserção, foi através de uma profissional que tinha, mesmo que sem compartilhar essas impressões com as demais pessoas, uma percepção semelhante: sobrecarga de trabalho, sofrimento, frustrações e sentimentos negativos que circulavam o ambiente de trabalho.

"Por alguns momentos é possível sentir na pele o quanto é difícil estar nesse espaço nesse momento" (Fragmento do Diário de Campo). Falar de um serviço que lida com o sofrimento batendo a porta nunca é fácil. Muitas vezes a forma que as pessoas encontram para lidar com seus próprios sentimentos em ambientes assim é se isolar física e afetivamente, numa tentativa frustrada de deixar a dor naquele local (Oliniski \& Lacerda, 2006; Amaral et al., 2008; Silva et al., 2015).

Completando o quadro, fala-se de um local em que as adversidades que provém de um contexto sociopolítico estão estampadas sem pudores: excesso de demanda, profissionais atarefados, cobrança por ultraprodutividade, salários e/ou benefícios atrasados, falta de materiais básicos para atendimentos, entre outros. Isto qualifica o sofrimento dos trabalhadores assistenciais e solidifica o distanciamento entre o que é esperado da atenção básica e a realidade que se impõem sobre ela (Damascena \& Vale, 2020). Não se pode ignorar o período de precarização exacerbada que se coloca, recaindo diretamente em políticas públicas que buscam viabilizar os direitos conquistados pelas classes trabalhadoras.

Segundo Mendes (2008), o trabalho tem diferentes sentidos para os trabalhadores, sendo que, na lógica capitalista, é possível perceber manifestações emancipadoras ou escravizantes. Assim sendo, quando se está em ambientes que prezam pela produtividade e se sujeitam a flexibilidade, há uma constituição de lógicas baseadas no "atingir de metas" e, com isso, trabalhadores estarão mais submissos a um fazer que vai antemão àquele de resistência e emancipação.

Tudo isso se reflete no laboral conforme as pessoas vão deixando de se sentir valorizadas e reconhecidas, até mesmo se sentindo desrespeitadas enquanto profissionais, ficando exaustas e em sofrimento intenso. As palavras "frustração" e "tensão" surgem muito nas escritas do diário de campo, e é esse o sentimento que o local passa, fazendo com que se pense que é assim que aquelas pessoas se sentem.

Como iniciar uma aproximação com o tema de saúde do trabalhador neste cenário foi um ponto amplamente refletido nas preceptorias e supervisões acadêmicas. Havia o temor de que qualquer tentativa de cuidado pudesse refletir em um desconforto, mexendo naquilo que pouco se é mencionado abertamente. Nota-se o quanto é difícil pensar em espaços de cuidado quando não se pensa juntos a pessoas, principalmente se a última coisa desejada é fazer uma imposição, com a ilusão de que é uma ação específica que irá milagrosamente gerar transformações.

Desse modo, inicia-se timidamente o fomento a espaços como reuniões de equipe macro ou micro, estimulando para que elas se dessem com a frequência prevista, mesmo na ausência de pautas, que pudessem ser um espaço em que essas pessoas se deslocassem de suas salas para se encontrar e se expressassem sem temer retaliações, um espaço de pausa. É através de encontros que é possível realizar trocas, sejam de informações ou de afetos, e quando se fala de uma equipe multidisciplinar que é responsável pelo atendimento de milhares de pessoas, o diálogo é um fator essencial para um funcionamento mais harmônico dos processos de trabalho.

Quanto maior o diálogo entre colegas de trabalho e chefias sobre a organização do trabalho, maior é a tendência de que essas pessoas se sintam satisfeitas. O reconhecimento está na alçada das relações e, propriamente por isto, não se deve deslocar os espaços de troca desse quadro (Ferreira, 2008; Mendes 2008).

O próximo passo, que se demorou a planejar, foi proporcionar um espaço acolhedor para que as pessoas pudessem de alguma forma colocar um pouco do peso que carregavam para fora. A desesperança dos trabalhadores e o sentimento de descrença da equipe frente ao trabalho também se fizeram presentes, remetendo novamente às experiências já mencionadas de Oliniski e Lacerda (2006). 
Foi difícil às residentes se perceberem no meio desse processo, muitas vezes pensando na desistência, e ouvir o quanto algumas pessoas poderiam perder a capacidade de se colocar no lugar do outro de forma empática, foi desestruturador, sendo necessário um esforço muito grande para não apontar possíveis causadores, mas sim olhar além e ver o porquê, para então trabalhar outros ângulos. A troca analítica do termo de culpabilização para responsabilização é de extrema simbologia ao permiti que as pessoas se tornem atores responsáveis em prol do bem-estar coletivo, diferentemente do que se daria em uma estrutura individualista pautada no afeto da culpa que desvalida o entorno, reflexões semelhantes aos disseres de Biagi \& Rasera (2018) ao pensarem sobre sua prática clínica no contexto sistêmico.

É corriqueiro daqueles que vêm com uma lógica intervencionista pensar em culpados, ignorando que essas situações se desenvolvem e agravam por conta de contextos - incluindo aqueles pelos quais se possui responsabilidade. Trabalhadores em sofrimento não são indivíduos isolados, são frutos das interações que se têm a partir de onde se está. Ter isso em mente se mostrou como primordial para pensar em ações que estivessem longe da lógica de apontar "causas dos problemas" ou "soluções mágicas", obviamente não efetivas.

$\mathrm{Na}$ ação, foi encontrado enquanto disparador o tema do cuidado à vida. Então se prepararam laços na cor amarela e vermelha que representariam isso - cores que remetem aos meses em que mais se discute cuidado e promoção à vida. Falou-se sobre esses significados e foi entregue para cada um dos membros da equipe esse laço. Foram feitas falas no sentido de que diariamente se cuida de outras pessoas, mas algumas vezes há o esquecimento do olhar para si e tentar perceber se tem algo que não está bem e o que é necessário fazer ou a quem é possível pedir ajuda para que isso melhore.

Em seguida foi feito em conjunto a "dinâmica das flores", que consiste em papéis recortados no formato de flores com escritos no miolo e as pétalas dobradas sobre ele, deixando difícil a percepção de que é uma flor. Após cada uma das pessoas pegarem uma dobradura é necessário colocar na água. Ao colocá-la em contato com a água, há um revelar-se flor e as palavras escritas aparecem, sendo que cada um deve comentar a que surgiu na flor que escolheu. As palavras utilizadas foram: valorização, acolhimento, escuta, equipe, cuidado, saúde, respeito, direito, motivação, compromisso, responsabilidade, satisfação, desafio, reconhecimento, competência, compreensão, simplicidade, confiança, ética, vida, comunicação, gentileza.

Todos os membros da equipe participaram e foi um momento em que todos conseguiram se manifestar de alguma forma. Os sentimentos que essa dinâmica causou foram variados: algumas pessoas mostraram abertamente o sofrimento que estavam sentindo, sendo um momento comovente para todos, enquanto outras preferiram expressar uma gratidão jamais revelada pelo acolhimento recebido quando se inseriram na equipe.

Houve espaço para poder falar sobre si, sobre o quanto alguns processos causavam dor e impossibilitam o sentimento de prazer em pertencer à equipe. Falou-se sobre o precisar de ajuda, o não conseguir mais lidar com algumas coisas sozinhos. Houve momentos de choro, riso, abraço e até mesmo pedidos de desculpas.

Chamou atenção o quanto não era costumeiro lidar com aquelas emoções para os profissionais da equipe, e foi necessária a interferência das residentes quando uma trabalhadora se emocionou, sendo que uma das soluções pensadas foi deixar que ela falasse no final, para quando ficasse mais calma. Assim, cabe a reflexão sobre como o sofrimento laboral pode ocorrer de forma velada diante de uma sociedade do espetáculo, em que a alegria é celebrada e há uma tendência à repressão diante da expressão de angústias (Bouyer, 2010). "É difícil nos sentirmos impotentes, não sabemos o que fazer, ficamos constrangidos porque não podemos apagar a dor do outro, e nem sempre pensamos em uma solução mais 'simples' de simplesmente ouvirmos, acolhermos, e dizer que estamos disponíveis para o que for necessário" (Fragmento do Diário de Campo).

Quando se utiliza de disparadores como palavras que têm em si diversos significados e por si só expressam vários sentimentos - como na dinâmica - tem-se um risco grande de que caso o ambiente não seja acolhedor ou não esteja preparado para ouvir o que vem disso, aconteça o efeito rebote e as pessoas se sintam ainda mais sozinhas e magoadas. Essa dinâmica 
despertava esse medo, mesmo após algum tempo construindo uma relação com essas pessoas, sabe-se do risco em se expor para quem não há um vínculo ou relação harmoniosa. Nessa medida, sinaliza-se o quanto é essencial que as práticas planejadas estejam de acordo com uma robusta sustentação teórica e supervisão clínica.

A dinâmica foi finalizada com café da manhã coletivo, algo que nas seguintes reuniões acabou se tornando um hábito, compartilhando alimentos e se permitindo ouvir. Avaliou-se como importante ter tido esse espaço de troca, feedback recebido também da equipe. Momentos em que é possível falar sobre o quanto certas atitudes afetam é o que permite a mudança, tendo em vista os afetos dos demais ao redor, assim como é possível fortalecer - ou iniciar - a construção de um sentimento de coletivo, que permite a união para conquistar objetivos em comum, reivindicar direitos, lutar por melhorias na saúde, entre outros.

Algumas mudanças foram notórias. A política do "bom dia" começou a entrar em vigência, mesmo quando não era necessariamente um dia bom. A disposição da sala de reuniões mudou, as pessoas não se sentaram mais nos corredores ou próximas a porta, mas próximas aos colegas. Fomentou-se espaços em que os colegas conseguissem compartilhar um pouco das dificuldades profissionais e pessoais, espaço esse que vem sendo construído timidamente e ocupado principalmente por agentes comunitárias de saúde. Houve mais comemorações de aniversários. E, por fim, as pessoas iniciaram um movimento para se ouvir mais nas reuniões, deixando o diálogo menos caótico e circulando a palavra.

Por mais que algumas ações tenham sido pontuais, diversos movimentos foram pequenos e feitos ao longo do dia a dia de trabalho, aproximando pessoas em uma sala em comum, propondo a escuta dos colegas que estavam em um grande sofrimento psíquico e pensando juntos em como auxiliá-los, assim criando mais espaços de trocas. Reforça-se a centralidade do trabalho na vida dos sujeitos, inclusive para a construção de sua identidade e vinculações sociais, e a necessidade de constante reflexão crítica sobre a sociedade em que se vive e como isto interfere nos cotidianos de trabalho (Giongo, Monteiro \& Soborosa, 2015).

\section{Considerações Finais}

Pensar saúde do trabalhador se coloca como um desafio também na medida em que se há uma implicação no processo de construção da saúde de uma forma integral. É curioso pensar que esses pedidos tenham alcançado até as profissionais que chegam, como se a busca de cuidado estive sendo solicitada há muito tempo e para diversas instâncias, que por vezes não escutam, e quando consegue se sensibilizar e ouvir, nem sempre conseguem pôr em prática com os recursos que alegam ter.

Enquanto residente, existiu a proposta do pensar além, apoiando-se no fato de que o fazer desse profissional tem um cunho ético e político que jamais poderá ser desprezado. Assim, o incômodo papel daquele que é passageiro também vem para a desacomodação, questionando, percebendo lacunas e propondo micro revoluções cotidianas. A inauguração desses espaços de trocas, escuta e pausa foi essencial para o andamento daquelas equipes em si, demonstrando o quanto tais atividades são exequíveis quando há engajamento e preocupação.

Ademais, coloca-se o quanto a residência, na modalidade de ensino em serviço que é uma estratégia de saúde pública, possui o papel de formação permanente aos futuros servidores e, também, aos trabalhadores da rede de saúde. As indagações nem sempre remetem a respostas, mas frequentemente a debates calorosos e propostas de cuidado, pautados em uma atuação na clínica ampliada em saúde e com robustez e aprofundamento teórico sanitarista.

Compreendendo que os sujeitos têm em si suas subjetividades, carregando consigo pensamentos dos quais só eles têm conhecimento, este trabalho seguiu uma estrutura coletivizadora ao invés da corriqueira postura culpabilizadora. Em tempos em que a uniformização se torna padrão, esses sujeitos resistem e não se permitem tornar-se um, gritam e assumem que têm necessidades, e que querem e vão ser ouvidos. Seria então esse "sofrimento" resistência? Quem afinal determina o que é estar sadio em uma sociedade adoecida? 
A presente vivência foi de suma importância para a qualidade formativa das profissionais, especialmente no sentido de pensar que para a concretização de políticas de humanização, faz-se necessário olhar de quem cuida e como estão suas vivências frente ao trabalho. Coloca-se que esta não é uma experiência que objetiva uniformizar intervenções ou sequer generalizar resultados, mas sim oferecer propostas e ponderações. Por fim, sugere-se como agenda de pesquisa, debates acerca da saúde mental do profissional residente, frequentemente invisibilizado e precarizado no Brasil.

\section{Referências}

Amaral, M. X. G., et al. (2008). Reações emocionais do médico residente frente ao paciente em cuidados paliativos. Revista da SBPH, 11(1), 61-86.

Antunes, R. (2018). O privilégio da servidão. Boitempo.

Bardin, L. (2011). Análise de Conteúdo. Edições 70.

Barros, R. B. De, \& Barros, M. E. B. De. Da dor ao prazer no trabalho. In: Santos-Filho, S. B., \& Barros, M. E. B. De (Org.) Trabalhador de Saúde, muito prazer! Protagonismo dos Trabalhadores na Gestão do Trabalho em Saúde (pp. 61-71). Unijuí.

Barros, A. C. F. de, \& Bernardo, M. H. (2017). A lógica neoliberal na saúde pública e suas repercussões para a saúde mental de trabalhadores de CAPS. Revista de Psicologia da UNESP, 16(1), 60-74.

Bastos, R. A., Quintana, A. M. \& Carnevale, F. (2018). Angústias Psicológicas Vivenciadas por Enfermeiros no Trabalho com Pacientes em Processo de Morte: Estudo Clínico-Qualitativo. Trends in Psychology [online]. 26 (2), 795-805.

Bendassolli, P. F. (2012). Reconhecimento no trabalho: perspectivas e questões contemporâneas. Psicologia em Estudo. 17(1), 37-46.

Biagi, B. A. D. \& Rasera, E. F. (2018). A construção da responsabilidade relacional em terapia familiar. Pensando familias, $22(1), 3-17$.

Bottcher, E., \& Monteiro, J. K. (2020). Engajamento no trabalho em gestores: influência de recursos pessoais e do trabalho. REVISTA PSICOLOGIA: ORGANIZAÇÕES E TRABALHO. 21, 1327-1335.

Bouyer, G. C. (2010). Contribuição da Psicodinâmica do Trabalho para o debate: "o mundo contemporâneo do trabalho e a saúde mental do trabalhador". Revista Brasileira de Saúde Ocupacional [online]. 35(122), 249-259.

Brasil (2001). Lei $n^{\circ} 10.216$, de 6 de abril de 2001.

Brasil (2005). Lei $n^{o} 11.129$, de 30 de junho de 2005. Institui o Programa Nacional de Inclusão de Jovens - ProJovem, cria o Conselho Nacional da Juventude CNJ e a Secretaria Nacional de Juventude, altera as Leis nos 10.683, de 28 de maio de 2003, e 10.429, de 24 de abril de 2002, e dá outras providências. Diário Oficial da União.

Brasil. (2007). Portaria $n^{\circ}$ 45, de 12 de janeiro de 2007. Dispõe sobre a Residência Multiprofissional em Saúde e a Residência em Área Profissional da Saúde e institui a Comissão Nacional de Residência Multiprofissional em Saúde. Diário Oficial da União.

Brasil. (2009). Portaria $n^{\circ}$ 1.077, de 12 de novembro de 2009. Dispõe sobre a Residência Multiprofissional em Saúde e a Residência em Área Profissional da Saúde, e institui o Programa Nacional de Bolsas para Residências Multiprofissionais e em Área Profissional da Saúde e a Comissão Nacional de Residência Multiprofissional em Saúde. Diário Oficial da União.

Brasil. (2012). Portaria $n^{o} 1.224$, de 03 de outubro de 2012. Altera a Portaria Interministerial $\mathrm{n}^{\mathrm{o}} 1.077$, de 12 de novembro de 2009 , e a Portaria Interministerial $\mathrm{n}^{\circ}$ 1.320, de 11 de novembro de 2010, que dispõem sobre a Comissão Nacional de Residência Multiprofissional em Saúde - CNRMS. Diário Oficial da União.

Ceccim R. B. (2010). A educação permanente em saúde e as questões permanentes à formação em saúde mental. Caderno Saúde Mental [online]. 3(1):67-90.

Damascena, D. M. \& Vale, P. R. L. F. (2020). Tipologias da precarização do trabalho na atenção básica: um estudo netnográfico. Trabalho, Educação e Saúde [online], 18(3).

Dejours, C. (1991). A loucura do trabalho. Cortez Editora.

Dejours, C. (2014). Trabalho, Tecnologia e Organização: Avaliação do trabalho submetida à prova do real (2nd ed., L. I. Sznelwar \& F. L. Mascia, Eds.). São Paulo: Blucher.

Dourado, A. D., \& Zambroni-de-Souza, P. C. (2020). Motivação e trabalho: investigação sobre a experiência dos jovens no primeiro emprego. Psicología, Conocimiento y Sociedad, 10(2), 5-20.

Ferreira, M. C. "Chegar feliz e sair feliz do trabalho": Aportes do Reconhecimento no Trabalho para Uma Ergonomia Aplicada à Qualidade de Vida no Trabalho. In: Mendes, A. M. (Org.) Trabalho e saúde: O sujeito entre emancipação e servidão. Curitiba: Juruá, 2008. $1^{a}$ ed., p. 40-53.

Giongo, C. R., Monteiro, J. K. \& Sobrosa, G. M. R. (2015). Psicodinâmica do Trabalho no Brasil: revisão sistemática da literatura. Temas em Psicologia. 23, 803-814.

Gomez, C. M., Vasconcellos, L. C. F. de \& Machado, J. M. H. (2018). Saúde do trabalhador: aspectos históricos, avanços e desafios no Sistema Único de Saúde. Ciência \& Saúde Coletiva. 23(6), 1963-1970. 
Research, Society and Development, v. 10, n. 14, e500101422417, 2021

(CC BY 4.0) | ISSN 2525-3409 | DOI: http://dx.doi.org/10.33448/rsd-v10i14.22417

Heloani, R. \& Lancman, S. (2004). Psicodinâmica do trabalho: o método clínico de intervenção e investigação. Production. 14(3), 77-86.

Martinez, M. C., \& Paraguay, A. I. B. Z. (2003). Satisfação e saúde no trabalho: aspectos conceituais e metodológicos. Cadernos de Psicologia Social do Trabalho, 6, 59-78.

Martins, C., \& Waclawovsky, A. (2015). Problemas e Desafios Enfrentados pelos Gestores Públicos no Processo de Gestão em Saúde. Revista De Gestão Em Sistemas De Saúde, 4(1), 100-109.

Mendes, A. M. Prazer. (2008). Reconhecimento e Transformação do Sofrimento no Trabalho. In: Mendes, A. M. (Org.) Trabalho e saúde: O sujeito entre emancipação e servidão (pp. 13-25). Curitiba: Juruá.

Mendes, A. N. (2016). A saúde pública brasileira num universo "sem mundo": a austeridade da Proposta de Emenda Constitucional 241/2016. Cadernos de Saúde Pública [online]. 32(12).

Merhy, E. E. \& Franco, T. B. (2003). Por uma Composição Técnica do Trabalho Centrada nas Tecnologias Leves e no Campo Relacional. Saúde em Debate, 27(65).

Monteiro, J. K., \& Vieira, F. O. (Org.), Mendes, A. M. (Org.). (2015). Trabalho \& Prazer - Teoria, Pesquisas e Práticas. Juruá.

Oliniski, S. R., \& Lacerda, M. R. (2006). Cuidando do cuidador no ambiente de trabalho: uma proposta de ação. Rev. bras. enferm. 59(1), 100-104.

Patricio, S., \& Gregoviski, V. R. (2020). A Precarização do Trabalho e da Saúde. In: Mattos, A. C. E., Gregoviski, V. R. (Org.). A Saúde Mental em Evidência: Narrativas de um Caminho Utópico. (pp. 53-63). São Leopoldo: Casa Leiria.

Pires, D. E. P. de et al. (2019). Gestão na atenção primária: implicações nas cargas de trabalho de gestores. Revista Gaúcha de Enfermagem [online]. 40.

Ribeiro, A. C. de A. et al. (2011). Resiliência no trabalho contemporâneo: promoção e/ou desgaste da saúde mental. Psicol. estud. 16(4), 623-633.

Rollo, A. de A. (2007). É possível valorizar o trabalho na saúde num mundo "globalizado"? In: Santos-Filho, S. B., Barros, M. E. B. De (Org.) Trabalhador de Saúde, muito prazer! Protagonismo dos Trabalhadores na Gestão do Trabalho em Saúde (pp. 19-59). Ijuí: Unijuí.

Santos, M. F. R. dos, \& Kuhn, M. F. (2021). Saúde como direito humano: vivências do cotidiano no SUS. Research, Society and Development, 10(12).

Silva, C. T. da et al. (2016). Residência Multiprofissional Como Espaço Intercessor Para A Educação Permanente Em Saúde. Texto \& Contexto - Enfermagem [online]. 25(1).

Silva, R. P. da, Barbosa, S. C., Silva, S. S., \& Patrício, D. F. (2015). Burnout e estratégias de enfrentamento em profissionais de enfermagem. Arquivos Brasileiros de Psicologia, 67(1), 130-145.

Silva, C. A. da \& Dalbello-Araujo, M. (2019). Programa de Residência Multiprofissional em Saúde: o que mostram as publicações. Saúde em Debate [online]. 43(123), 1240-1258.

Sousa, K. O. de, \& Barros, L. M. (2018). Estresse e Estratégias de Enfrentamento de Gestores de Saúde. Estudos e Pesquisas em Psicologia, 18(2), 496-515. 